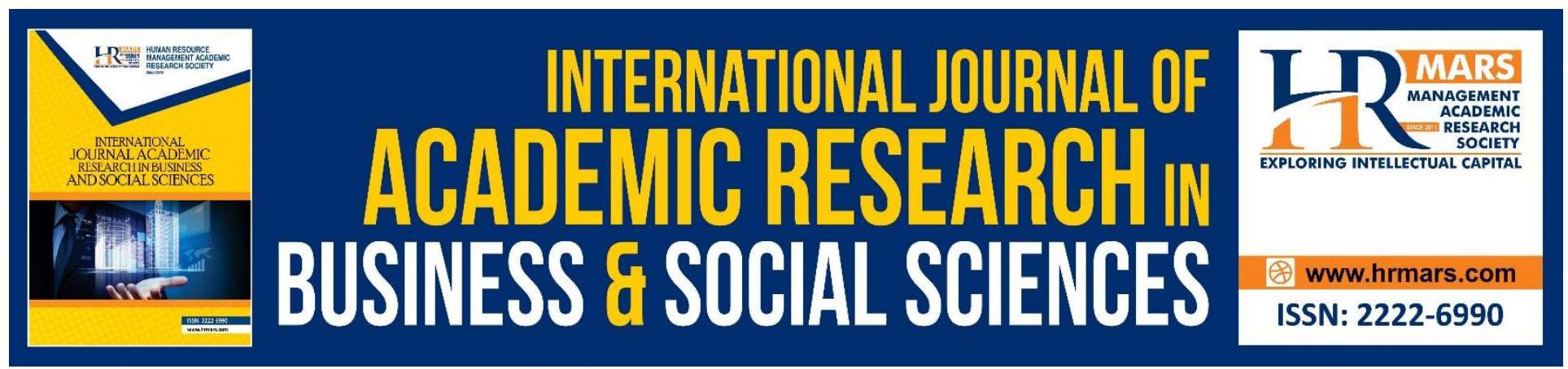

\title{
The Application Systems with Industrial Revolution 5.0 In Supporting Youth Development Environment
}

\section{Rusli Abdullah}

To Link this Article: http://dx.doi.org/10.6007/IJARBSS/v11-i15/10653

DOI:10.6007/IJARBSS/v11-i15/10653

Received: 13 May 2021, Revised: 19 June 2021, Accepted: 01 July 2021

Published Online: 27 July 2021

In-Text Citation: (Abdullah, 2021)

To Cite this Article: Abdullah, R. (2021). The Application Systems with Industrial Revolution 5.0 In Supporting Youth Development Environment. International Journal of Academic Research in Business and Social Sciences, 11(15), 285-292.

Copyright: (c) 2021 The Author(s)

Published by Human Resource Management Academic Research Society (www.hrmars.com) This article is published under the Creative Commons Attribution (CC BY 4.0) license. Anyone may reproduce, distribute, translate and create derivative works of this article (for both commercial and non-commercial purposes), subject to full attribution to the original publication and authors. The full terms of this license may be seen at: http://creativecommons.org/licences/by/4.0/legalcode

Special Issue: Empowering Youth and Community Wellbeing for Sustainable Development, 2021, Pg. 285 - 292 http://hrmars.com/index.php/pages/detail/IJARBSS

Full Terms \& Conditions of access and use can be found at http://hrmars.com/index.php/pages/detail/publication-ethics 


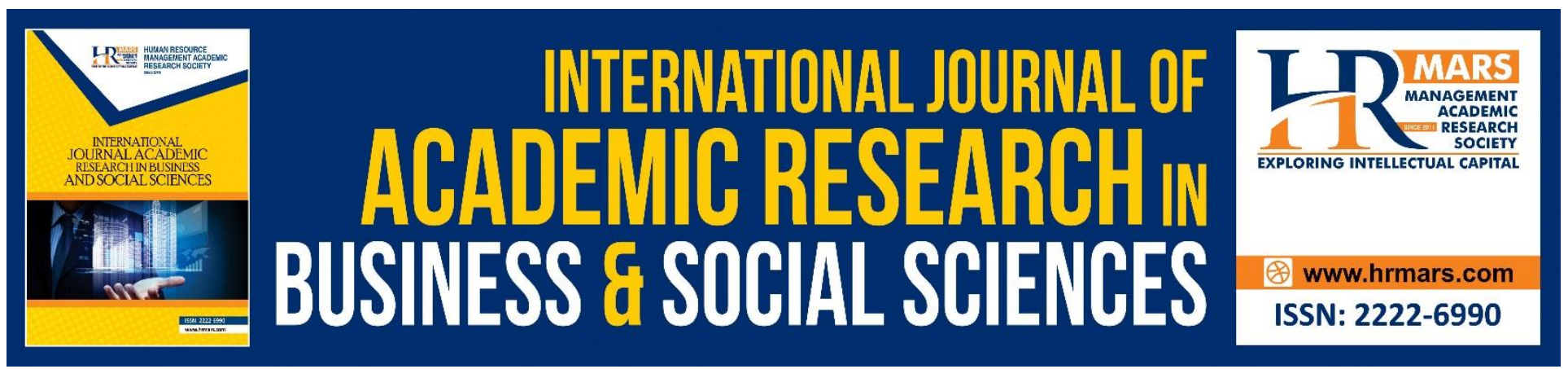

\title{
The Application Systems with Industrial Revolution 5.0 In Supporting Youth Development Environment
}

\author{
Rusli Abdullah \\ Faculty of Computer Science and Information Technology, University Putra Malaysia, \\ Serdang, 43400 Selangor, Malaysia, Institute for Social Science Studies, Putra Infoport, Universiti \\ Putra Malaysia, 43400 UPM Serdang, Selangor, Malaysia. \\ Email: rusli@upm.edu.my
}

\begin{abstract}
The role of Information Communication Technology (ICT) in our life is very important and nowadays it is required to be used anywhere, through any platforms and anytime especially in relation to Youth Community of Practice (YCoP) activities in enhancing their future quality of life. Meanwhile, for social development of the youth and preparation to become a leader of tomorrow, ICT of Application System (AS) with Industrial Revolution (IR5.0) plays a big part in their journey in ensuring no one is left behind and always ready to face new issues and upcoming challenges in the future. Besides that, based on the reviews of the related papers done, there is an indication that the need of the AS is becoming increasingly important and could not be avoided in YCoP environment. Therefore, Application Systems with IR 5.0 is considered essential in assisting the youth for their activities of future development environment purposes and consequently this will ensure their quality of life can be improved and sustainable all the time.
\end{abstract}

Keywords: Application System, Information System, Industrial Revolution, Youth Community of Practice, ICT.

\section{Introduction}

Nowadays, ICT has played a major role in our life and become a common tool for everyone to use and utilize anytime, anywhere and through any available platforms especially related to Youth Community of Practice (YCOP) activities in enhancing their future quality of life. The used of ICT especially in related the Application System (AR) with IR5.0 is helping or supporting a lot of the YCoP to ensure all of their activities can be done effectively and significantly. On top of it, based on the reviews of the related papers that has been carried out, there is an indication that the need of the AS is becoming increasingly important and could not be avoided in YCoP environment.

Hence, in order to help the reader to understand in detail of the used of ICT based on its AP with IR5.0 for supporting YCoP, the paper is will discuss the literature review as a section, followed by research methodology section, and continued with results and discussions based on issues and challenges sections as well as conclusion as a final section with regards to the ICT application with IR5.0 for the purposes of YCoP environment. 


\section{Literature Review}

For the purpose of the literature review in explaining the relationship of ICT application with IR5.0 for youth development environment, the conceptual definition of these terminologies will be discussed based on the components as follows:

\section{What is Application Systems?}

Application (App) System (Sys) is a created or customized software that has been developed on top of hardware platform in order to help youth for specific purposes of their activities.

This application software or in short called as App Sys has been developed based on the following functionalities:

- For learning or education either online or offline purposes is called as e-learning

- For online gaming or sport purposes is called as E-Games or e-Sport

- For online entertainment to fulfil their leisure time is called as E-Entertainment

- For online shopping purposes is called as E-Shopping

- For managing and recording of healthcare through online platform is called as EHealth

- For managing and conducting the online business is called as E-Business

\section{What is IR5.0?}

This is the Industrial Revolution (IR) 5.0 with regards to the technology aspects that is offered to the people especially Youth Community of Practices (YCOP) with the latest technologies such as artificial intelligence (Al), cloud computing, system integration, big data and internet of things (Baygin, Yetis, Karakose, and Akin, 2016; Price Water House,2014).

Consequently, it can be developed as a smart environment by using smart technology as stated above. Through IR5.0, YCoP can use it for personal or collaborative purposes in their lives to improve the quality with effective and efficient manner.

\section{What is Youth Community of Practice (YCoP)?}

YCoP is the community of Youth members that are working together to achieve their missions of the business for future development environment based on a specific purpose.

In this context, it is clear that the use of ICT or App Sys is very important part as enabler or tool to support the members of YCoP for their activities which related to the purposes of future development environment particularly in education purposes (Fisk, 2020; MOHE, 2017).

\section{Research Methodology}

In order to develop a proposed model of application system for supporting the YCoP, a review of the literature based on their importance in relation to ICT and IR5.0 environment has been performed in this area of research. These include extracting data from secondary platform which are in the form of softcopy and hardcopy especially information and knowledge that is available through the internet as well as other related issues and its challenges throughout documentation explicitly (Fazel Ansari, 2019). The data which have been gathered are then being analysed accordingly. Furthermore, further categorization also has been performed based on the related system application or utilization together with their related business purposes based on issues and challenges that are expected to be faced by YCoP for their current requirement or use, and for the purposes of using ICT of the future. 


\section{A proposed model of Application system with IR5.0 to support Youth Development Environment for their activities.}

Based on the review that has been done, the proposed model of application system with IR5.0 related to the Youth development activities is developed which can be categorized into several systems. The model and its application system is shown in Figure 1.

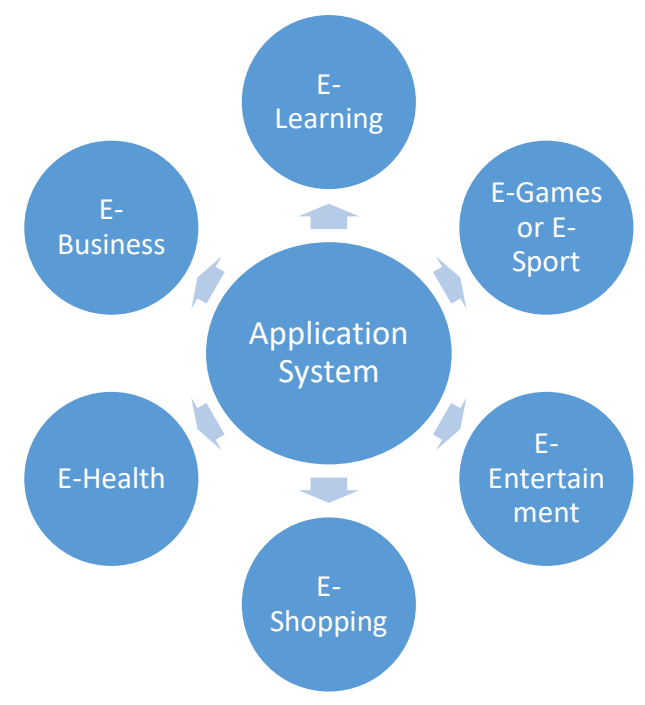

Figure 1: A proposed model of application system

The beauty of these applications with IR5.0 as a system model is that it can be promoted by a notification or an alert process as well as personal and collaborative recommendations by using $\mathrm{Al}$ technology in servicing the business for its survival and sustainability.

These are the applications required by the YCoP in a real life which have been developed as follows:

- $\quad$ E-Learning

This is the application system that is developed for supporting the YCoP not only to acquire the knowledge, but also to allow them to learn and assess the knowledge by using an integrated system that includes payment structure as well as course or subject content management and for examination purposes entirely. The good example of this application system is learning management system (LMS). The LMS is a system that acts as a platform for youth to communicate with their teachers or lecturers for the purpose of teaching and learning environment. This means that they can learn anytime and anywhere in 24/7 environment.

- E-Games or e-Sport

This is an application system that allows the YCoP to play game online together anytime, anywhere without requiring their physical presence at the same location. They can manage and register to play by using multi player mode at the same time and at different place by using the internet. The most popular tool right now is the PS5 device and their associated technologies.

- E-Entertainment 
This is an application system that allows the YCoP to fill their leisure time to watch the movies online. The application also allows them to purchase the video in advance and have it watched later. This is called as Video on Demand (VOD). This enables them to either watch the video online during the screening time or enjoy the video offline or at later time based on their availability. Besides that, they can also create e-studio for content management and make use of e-media in disseminating the video as e-content platform environment.

\section{- E-Shopping}

This is an application system that allows the YCoP to shop online and avoid the YCoP from moving physically for their shopping purposes. This application also will allow the shopping complexes or malls to be opened $24 / 7$ and at the same time promoting the use of cash or money electronically (e-cash). Consequently, this will also promote the businesses which is called as Gig economy. This is very relevant and significant job for youth environment. The good example here is Lazada, Shopee and Amazon.

- E-Health

This is an application system for recording and managing the healthcare of YCoP remotely to ensure that they can monitor their own health either every day, every week or every month. In this context, the YCoP also can utilize the application to monitor their food consumption for diet purpose and also anything related to healthcare environment. The good apps right now are like a personal doctor or telehealth that seeks the professional advice and treatment locally and globally.

\section{- E-Business}

This is an application system for supporting the YCOP to perform a business online or electronically. The business can be done in relation to selling or buying the products and services by using web site or blog that is provided to commerce them for free. Besides that, they can also be leveraged by a third-party platform such as a social media that allows them to provide the goods or services online to other parties. In this context, they can also choose to become as an agent or broker for promoting as well as selling, buying and shipping the product bought by others parties based on specific customers. This eventually enables them to promote in term of ecommerce which is related to business to business (B2B), business to customer (B2C), and customer to customer $(\mathrm{C} 2 \mathrm{C})$. At the same time, they also promote the concept called as emarketplace.

\section{Result and Discussion based on Issues and Challenges}

In the context of application system for Youth activities, there are three aspects of issues and their challenges to ensure they can shape the future purposes as shown in Figure 2. 


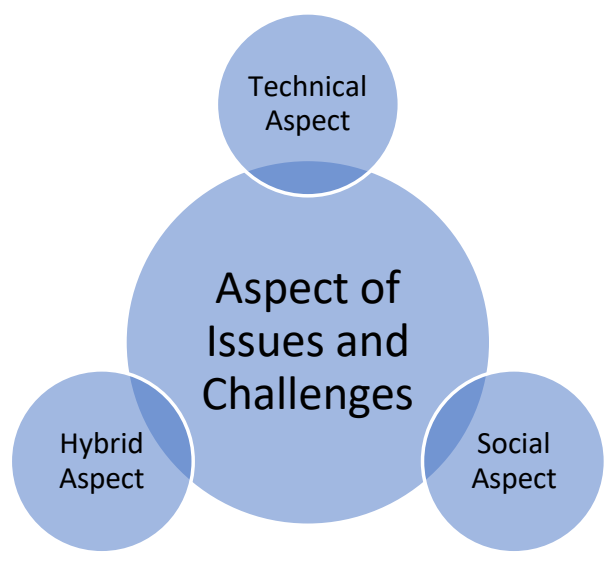

Figure 2: The three main aspects of Issues and Challenges

The issues and challenged are categorized into three aspects as follows:

- Technical Aspect.

The technical aspect is related to the issues on operational methodology and sometimes requires a little bit of coding to ensure that the hardware and software can have the connection with each other for its functions or processes specifically.

- $\quad$ Hardware is the most important part of a device or tool that needs to understand on how to use or operate for a specific functionality. Normally, the hardware can be looked in term of its abilities and capabilities like power, memory, and its connectivity like WIFI and Bluetooth. The most popular hardware nowadays is called as gadget like Smart Phone, Smart PC, Tablet and anything that can be connected for a special purpose.

- $\quad$ The software is another technical aspect that is required to be understood by YCoP especially with regards to operating system (OS) as a platform in order to run or implement the additional software or package like application system based on its specific functionality. The most popular OS right now is the one that is related to Smartphone application such as Android and IOS for Apple iPhone. Normally, a user or customer can use the built-in application for browsing through any kinds of browsers like Internet Explorer for downloading or uploading information. Besides that, the user also can utilize Google Play Store or Apps Store for downloading the application system which is offered by the application system provider for the user to use for a specific requirement and functionality.

- Internet is a very important aspect that is required by the YCoP in order to get full enjoyment of application system which is available for them to use for free or sometimes require them to pay minimum cost for extra features like bring of your own devices (BYOD). The internet is also useful to ensure the hardware or device as a gadget is connected to each other. Normally, they are connected through unwired channel which called as WIFI or Bluetooth for short distance connectivity. To stay connected all the time, normally YCoP has to use the Internet that has been offered by Internet Service Provider (ISP) like Celcom, DIGI or Unifi. The connectivity will be based on their datalink of transmission speed called 3G, 4G and 5G. The higher the data link of G's will be better but more expensive. 
Social Aspect

The social aspect is related to the issues on how to ensure that the operation can be done smoothly with the desired effectiveness, efficiency as well as its ethicality.

- $\quad$ The motivation issue is a social aspect that is needed to ensure that YCoP can use the application system continuously. This is also to ensure the YCoP will be using the application system all the time and it is normally to encourage them to utilize the technology for any purposes of their lives. Consequently, they will be content and willing to promote these kinds of technologies among them including their peers. They also can be as a promoter to run the business electronically and at the same time specifically improve their quality of life.

- $\quad$ The financial issue is another aspect of social issues that is related on how to encourage and ensure all the application system which are offered to the members of YCoP can be fully utilized. As a result, everyone can reap the benefits in term of their return of investment (ROI) for a specific functionality of application system. At the same time, the goods or services can be offered at lower prices since there is no requirement of a lot of manpower in serving the YCoP for specific business requirement purposes electronically and virtually.

- $\quad$ There is another very important aspect in socialization process which is related to make use the application systems ethically. Supposedly the users need to be responsible in using application system based on their awareness which is either right or wrong of doing something. Therefore, we can promote the ecosystem environment on any kind of application system with trustworthy and safety. In another word, we are trying to promote the concept of respectability and integrity.

- $\quad$ Hybrid Aspect

The hybrid aspect is related to the issue on how to ensure that the technical and social aspects can work together safely and with integrity especially with regards to open-source software integration. This also means to ensure the operation based on a specific function can be monitored and working securely and respectfully. The Security issue is the main concern in application system with IR5.0 for YCoP activities in order to ensure that they are using the right product at the right time securely. This also will ensure that everyone is under control and manageable to use the application systems as a product or service securely and with trustworthiness.

Furthermore, the last issue of hybrids is related to Open-Source application systems environment. This issue will encourage people or user to use the right product at the right time particularly to promote the intellectual property right like patents and copyright of the product. As a result, mutual respect of YCOP in world of cyberspace can be created especially that is related to cybersecurity environment.

\section{Conclusion}

There are a lot of advantages that can be gained by YCoP in using the application system for their future development purposes. Certainly, there is a requirement for the YCoP to be aware and concerned about the issues and challenges as a critical success factor which is the main part to the application system in order it can be used or implemented successfully. With the understanding of this scenario, members of YCoP will maintain or sustain the benefits of using application system for their future development survival. 


\section{References}

MOHE. (2017). Higher Education 4.0 : Current Status and Readiness in Meeting the Fourth Industrial Revolution Challenges https://www.mohe.gov.my/muat-turun/awam/teks-ucapan-danslide/2017/redesign-higher-education-4-0/379-higher-education-4-0-current-status-andreadiness-in-meeting-the-fourth-industrial-revolution-challenges/file

Baygin, M., Yetis, H., Karakose, M., and Akin, E. (2016), “An effect analysis of industry 4.0 to higher education", Proceeding of 15th International Conference on Information Technology Based Higher Education and Training (ITHET), Portugal.

Ansari, F. (2019), Knowledge Management 4.0: Theoretical and Practical Considerations in Cyber Physical Production Systems, IFAC-PapersOnLine Volume 52, Issue 13, 2019, Pages 1597-1602

Price Water House. (2014). "Industry 4.0 - Opportunities and Challenges of the Industrial Internet" https://www.pwc.nl/en/assets/documents/pwc-industrie-4-0.pdf

Fisk, P. (2020). "Education 4.0 ... the future of learning will be dramatically different, in school and throughout life." https://www.thegeniusworks.com/2017/01/future-education-youngeveryone-taught-together/ 